\title{
TEMAS IMPORTANTES DE GEOGRAFIA RURAL NA BIBLIOGRAFIA RECENTE
}

(Parte II)

Continuamos a série de notas iniciada no número anterior de FINISTERRA, referentes a temas de Geografia rural abordados, recentemente, em livros de autores de diversa formação cientifica, tendo sempre em atenção que este ramo da Geografia "deve virar-se para outras disciplinas e comprometer-se na via interdisciplinar». Tal como procedemos na Parte I, referenciaremos com maior desenvolvimento a bibliografia menos acessivel.

A) A agricultura numa perspectiva ecológica

No prolongamento do tema $A$, abordado anteriormente, salientamos o novo livro de M. GOMEs GUmRrirno, Ecologia dos Recursos da Terra, publicado pela Comissão Nacional do Ambiente, na Colecção "O Ambiente e o Homem», Lisboa, 1979, 125 p., algumas figuras e fotografias bastante elucidativas e resumos em francês e inglês. Foi propósito do antor tratar a "Ecologia apenas na sura perspectiva biológica, como ciêneia que estudla a composição, a estrutura, o funcionamento e as condições de estabilidade dos sistemas naturais da biosfera, efectiva ou potencialmento fornecedores dos recursos» e proporcionar uconhecimento indispensável à formulaçño das regras e das estruturas sociais que correctamente assegurem ao Homem, em sociedade, as melhores condliçóes de dignidade, de conforto e de qualidade de vida, numa visão global projectada no futuros. O livro centra-se nos Recursos da Terra, nos sistemas que os fornecem, nos seus principais componentes e nalguns dos princípios que presidem no seu funcionamento.

Nas considerações Preliminares (p. 13-21), salienta-se que una cegueira de uma civilização de conforto altamente sofismada, até o próprio sector ngricola, naturalmente de resposta lenta e de fraca potência, passon a ser grandemente fustigado", que "o crescimento significa acumulação simnltânea de energia e de matéria, o quo a Física, a Natureza e o "bom senso» demonstram ser impossível num Mundo limitado», e ainda oue "o crescimento constante é portanto apenas a filosofia do impossível..., a não ser que se trate de crescimento para $o$ caos, se entendermos que tudo finda na morte».

Referindo-se especificamente à agrioultura, M. G. GuERREIro sublinha que ela "é hoje a àctividade do Homem que mais se aproxima dos sistemas naturais. Contudo, certos empresários, munidos de tecnologia de ponta, procuram artificializá-la no máximo na mira de aumentar $o$ produto líquido e assim garantir, no momento, a alimentação de uma populaçño mais numerosa e exigente. 
Para isso adicionam doses elevadas de energia concentrada, sob a forma de máquinas, nuitrientes, água e vários ingredientes químicos. Criam assim uma situaçño de grande intensidade de energia que carece de tantos ou mais cuidados que os sistemas artificiais, se quiser manter o equilíbrio dinâmico e produtivo sem resvalar para posições irreversivelmente desestabilizadoras. Mesmo que os produtos agrícolas possam manter o valor monetário no mercado, neste esquema o seu custo energético aumenta cada vez mais. Chegon-se ao desaforo de diminuir drasticamente, na agricultura dita progressiva, a relaçño entre a energia utilizável à saída e a energia adicionada à entrada.

A agricultura, que foi, durante milhares de anos, a actividade produtora de energia, a tinica, segundo os primeiros economistas, tornou-se igualmente, nos últimos anos, uma actividade altamente consumidora) (p. 19). Embora se saiba que as formas de energia fóssil são esgotáveis, se degradam com o uso e se perdem através da cadeia de produção (calor), 0 mundo tornou-se altamente "energívoro" e "a energia passon a ser considerada a chave milagrosa que abriria as portas da ventura a todos os homens $\theta$ a todas as sociedades (p. 14).

No capitulo seguinte, recorda-se a evolução das relações entre o «Homem e os Recursos da Terray (pp. 22-26), desde o Neolíticio até às sociedades hximanas modernas, não independentes dos sistemas biofísicos (embora relativamente libertas), aspecto que tom sido levianamente desprezado: "na verdade, 0 género humano [...] não possui capacidade para ucriar» no sentido biofísico on termodinâmico, podendo contudo valorizar, no seu conteúdo de utilidade, os elementos naturais, quer estes derivem directa on indirectamente do Sol quer dos processos telúricos que criaram e modelaram a superfície da Terra) (p. 23).

Seglem-se capítulos centrados em "A Biosfera e o Homem", "O Processo Evolutivo. Sucessão e Clímace» (fazendo notar "o enorme potencial genético, quer ao nível do indivídno quer ao nível do grnpo ou da associação», da fase clímace, particularmente importante na criação de variedades altamente produtivas, de qualidades válidas e adequada capacidade de adaptaçấo a determinados meios), o "Conceito de Sistema" ('), salientand., nomeadamente, quue "o percurso da energia na biosfera, iniciado nas plantas que a retêm sob a forma de energia química, continua por transferência para os animais herbivonos e depois para os carnivoros, até se perder na atmosfera, sob a forma degradada de energia térmica ou calor; ... que as plantas permitem manter a Terra no mesmo nivel elevado de energia útil...; e que a agricultura é a única tecnologia que permite acrescentar um valor quantitativo a outro existente (de energia) ..., que só esta actividade produz riqueza, pois que as restantes apenas transformam; e, ainda, que a quantidade total de energia récebida pela Terra é constante, mas a percentagem armazenada pode aumentar, dentro de certos limites, em função dos ecossistemas existentes». Recordam-se, em seguida, os princípios de funcionamento dos sistemas e a importância dos factores ecológicos (sobretudo, temperatura, humidade e solo).

O livro que estamos a apresentar termina pela "Classificação dos Siste-

(1) «Conjunto de elementos físicos e biológicos inter-relacionados e interdependentes, dispostos segundo a ordem que the é imposta por um programa da responsabilidade de uma informação sob a forma da mensagem veiculada por elementos heredittírios ao longo do sucessões. Nos objectivos que pretende alcançar contam-se a estabilitade e a perpetuidade.» mas» fornecedores de recursos (pp. 60-120), distinguindo e caracterizando os sistemas naturais, artificinis, mistos (ou agrossistemas), múltiplos ou integrados e os humanos, atendendo essencialmente às fontes de energia e aos materiais que utilizam.

Do ponto de vista agrícola, importam apenas os três últimos tipos. Torna-se-nos assim fundamental a leitura das págs. 83 e seguintes. Com o fim de a estimular, apresentamos alguns parágrafos particularmente significativos.

"Os sistemas mistos são sistemas naturais transformados pelo Homem que, para tal, utiliza conheoimento técnico-científico e doses progressivamente maiores de energia e de materiais ... O processo da manutenção destes sistemas em funcionamento tem-se sofisticado nos últimos tempos com a chamada agricultura intensiva ou industrial. Elevadas doses de energia e de materiais são aplicadas pelos tecnologistas agrários, sob a forma de máquinas, adubos, herbicidas, fitofármacos, sementes e plantas ditas "melhoradas», etc.". E, mais adiante, wos sistemas mistos fornecem no Homem, por intermédio da actividade deste e por transferência, a energia do Sol que, com a água e os materiais existentes no ar (carbono e outros) e no solo, absorvidos estes pelo aparelho radicular, formam a matéria orgânica..., a que recorre para a sua manutençũo, d̀s vezes indirectamente, por intermédio de animais herbívoros e nalguns casos até de carnívoros) (pp. 83-90).

Mas, "hoje, por todo o mundo da vanguarda tecnológica, o funcionamento do subsistema motor de um agrossistema depende muito do petróleo, embora o seu uso não seja compensado, em valor energético, pelo aumento

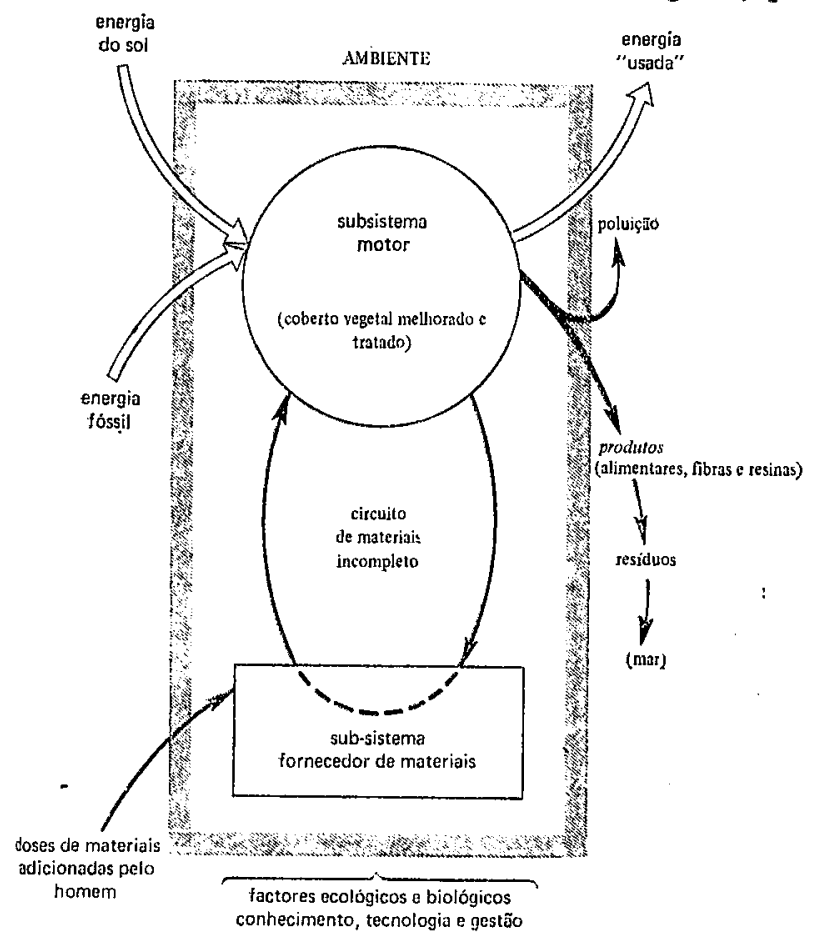


da produção. Adições excessivas de matérias apenas levam à poluiçãon (pp. 92-93).

"O grafico seguinte procura representar, esquematicamente, as fases mais típicas de um sistema misto ou natural intervencionado.

As três principais características que o distinguem do sistema natural são as seguintes:

a) Uso de doses complementares de energia, obtida principalmente do petróleo sob a forma de máquinas, utensílios e produtos químicos.

b) Adição suplementar de doses de materiais em quantidades volumosas, ou seja de elementos biogeoquímicos obtidos de jazidas, após tratamento tecnológico adequado em grandes unidades fabris, nem sempre com o melhor critério qualitativo.

c) Uso de elementos vegetais, geneticamente modificados (“melhorados" na terminologia do técnico agrícola), capazes de constituírem subsistemas motores homogéneos, rápidos e eficazes. A homogeneidade permite usarem-se os mesmos granjeios e cuidados culturais (portanto com diminuição de encargos de exploração) e obterem-se produtos padronizados de melhor aceitação nos mercados da sociedade em que vivemos" ( $\mathrm{p}, 95)$.

"A actividade descrita de intervenção do Homem nos sistemas naturais no sentido de os levar a fornecer produtos (alimento, fibras e resinas) denomina-se agricultura. Agricultura é pois, em sentido lato, a tecnologia que procura "melhorar» o gerir, com eficácia, os sistemas naturais de modo a neles reunir, em qualidade e em quantidade, energia do Sol e materiais da biosfera, em condições de poderem ser utilizados directa ou indirectamente na satisfação das necessidades da Humanidade.

Nesta actividade, o saber, ou o que por vezes se designa por "eficiência técnico-cultural», é dos parâmetros de que mais depende a produção e a produtividade do sistema; é função do conhecimento do Homem em termos de tecnologia, de biologia e de ecologia.

E pois inconcebivel que a actividade primária (agricultura, silvicultura e pesca) empregue os trabalhadores menos qualificados, mais idosos e portanto de menor criatividade. Sendo assim, como é possivel que o sector progrida? Como pode a sua produtividade igualar-se à dos restantes sectores?» (p. 96).

\section{B) Variações da população e do povoamento rural}

Estes temas foram desenvolvidos por HUGH D. ClovT, in Rural Geography: an Introductory Survey (Oxford, 1976, e, em espanhol, Oikos-Tau, SA-Ediciones, Barcelona, 1976,320 p. e 40 figuras). O livro compreendo uma extensa bibliografia no final de cada capítulo, classificada por assuntos, que permite a sua utilização a dois níveis: revisão dos temas rurais escolhidos e ponto de partida para investigações mais aprofundadas, se se dispõo de boas bibliotecas.

O autor iniciou-o com uma apreciação de conjunto da Geografia Rural (cap. 1, pp. 11-19), nomeadamente do seu âmbito e da actualidade de alguns assuntos habituais, no contexto dos países desenvolvidos, em especial nas Thas
Britânicas, onde desenvolvell a sua experiência de investigador. Quanto à importância que a Geografia Rural deve manter na ciência geografica, HUGH CLOUT anota que, no campo, ocorrem grandes mudanças sociais, económicas e no uso do espaço e que aquela se pode definir como o estudo do recente uso económico - social do solo e das mudanças espaciais (p. 12),formais (sob pressão ta procura para residências, indústrias, comunicações, instalações militanes e actividades recreativas) e funcionais (despovoamento e ruralização de aldeias remotas, com a partida de trabalhadores agrícolas e de artesãos e comerciantes; invasão por citadinos, com aparecimento de residências permanentes e secundárias, equipamento hoteleiro e complementar e instalações recreativas); estas acarretam mudanças sociais significativas, a difusão do estilo de vida urbana e alterações na relação homem-terra, pelo que pedem uma política de racionalização do uso do solo e de reorganização das estruturas agrárias (novas infra-estruturas do meio rural e novas exigências da agricultura moderna).

1. O despovoamento rural (cap. 2). As dificuldades de definição da população rural em diferentes contextos espaciais, históricos e culturais, traduzem-se nas de avaliação das suas perdas. Estas processam-se segundo tipos diferentes:

- despovoamento biológico, quando o saldo migratório não compensa os défices físiológicos, posteriores a êxodos prolongados de gente jovem, que deixam estruturas etárias muito desequilibradas e envelhecidas, de limitado potencial reprodutivo, como sucede em áreas pobres social e economicamente, e nada atractivas em termos migratórios;

- êxodo rural não profissional, envolvendo os jovens de áreas agrícolas densamente povoadas, pela dificuldade de emprego local enquanto persistir nma insuficiente diversificação das actividades económicas;

- êxodo rural profissional, abrangendo sobretudo certos grupos: proprietários e empresários, perante estruturas agrárias inadequadas; jornaleiros, em períodos de depressão económica, de cultivos e de emprego, on nos de progresso tecnológico, com a sua substituição por máquinas; artesãos, penante a diminuição da clientela, devida ao exodo, a desvalorizaç̃o dos seus serviços e a concorrência da produção fabril.

O autor nota ainda que o êxodo não corresponde a respostas automáticas a condições "repulsivas» do campo e atractivas da cidade e que tnão há forçosamente uma relação inversa entre o volume de partidas e a distância entre o campo de origem e o centro urbano de destino.

No êxodo da Inglaterra e do País de Gales verificou também o peso das deficiencias do equipamento tural, das reduções reais e aparentes dos aliciantes da vida no campo e de aspectos subjectivos, como a sua percepção e o processo de tomada de decisões. Resultaram reduções do tamanho médio das famílias, desequilíbrios na composição por idades e por sexos, alterações nos sistemas de posse da terra e de utilização do solo, bem como nas comunicações e outros serviços, etc.

Sistematizando, H. CLOUT salientou:

a) Diminuição da mão-de-obra agrícola, que se pode confirmar através de séries estatísticas agrupando os activos por sectores de actividade e por condi- 
ções profissionais no quadro dos mesmos sectores. Na Grã-Bretanha os máximos registaram-se na segunda metade do século XIX, no prolongamento da acumulação dos saldos demográficos do campo, da intensificação dos sistemas de cultivo da terra e do alargamento das áreas exploradas. Seguiu-se-lhes estagnação em termos absolutos, enquanto cresciam a população total e a urbana, pelos afluxos rurais, sobretudo nos períodos de crise (concorrência de produtos importados; difusão de pragas, etc.) e de mecanização. Quando da 2.. Grande Guerra, perante a necessidade de produção de alimentos, registaram-se máximos secundários de activcs agrícolas, mas não duradouros. Com as novas reduções contínuas acentuam-se as diferenças demográficas em relação ao século XIX, om termos de idade e sexo: as crianças e os jovens são retidos pela escola; muito trabalho das mulheres foi dispensado, após introdução de maquinaria.

b) Mudanças na estrutura económioa dos aglomerados rurais, afectando particularmente os artesãos, que outrona pnoduziam bens o asseguravam serviços aos habitantes do campo. Recorde-se que, antes da Revolução Industrial, as actividades manufactureiras distribuíam-se em função dos recursos hidráulicos, do carvão, incluindo o vegetal, e das matérias-primas (ex. têxteis, ferro, couros, moagens). Muitas das que se dispersavam pelo campo looalizaram-se posteriormente em portos e grandes concentrações urbanas. "O declínio da indústria manufactureira rural foi causa e efeito da diminuição geral da população do campo": concorrência da produção de origem fabril, de mais baixo custo; redução da clientela dos artesãos. "As empresas manufactureiras e os serviços garantiram, no passado, uma estrutura social aberta em muitas comunidades rurais. Tais actividades desapareceram completamente (...) ou adaptaram-se para satisfazer novas necessidades» (p. 33). Na Grã-Bretanha, na viragem do século, tinha começado um processo de ruralização: êxodo para a cidade dos rurais activos na indústria, no comércio e em outros sectores da economia rural mas persistência de agricultores e trabalhadores agricolas; nenhum movimento significativo de mudança de residência da cidade para o campo.

c) Deficiências do equipamento mual, embora se não devam esperar correlacões significativas entre as taxas de despovoamento e a existência e o nivel das habitações, infra-estruturas básicas, equipamentos e serviços. Numas sociedades verifica-se apreço pela diversidade e qualidade do equipamento, noutras não. “Não é possível considerar uma área como homogénea, um aglomerado como uma parte de uma só sociedade rural, excepto em termos muito gerais." $O$ autor distinguiu vários tipos de sociedades: integradas, em desintegração, fechadas e abertas, sendo mais desejável a aberta e integrada, que corresponde a aglomerados importantes, de população estável ou crescente, com sentido ć́vico, junta de freguesia activa, diversões, equipamento escolar e capaz de prestar serviços aos habitantes residindo nos pequenos núcleos vizinhos. Sem incentivos económicos, só um forte sentido de "comunidade" reteria no campo a sua população.

d) Reduções reais e aparentes dos aspectos atractivos da vida rural. Neste século, através do ensino obrigatório, dos jornais, da rádio e da televisão e da crescente mobilidade, a população rural apercebeu-se de que na cidade se dispunha de melhor equipamento comercial, assistência social, habitação, transportes, serviços, emprego, salários e possibilidades de contactos sociais e inte- lectuais. Nesta desigualdade de condiçóes de trabalho e de vida reside a causa do importante exodo rural, mas de modo difenente segundo a idade, sexo, posiçño social, nível de educação, aspirações económicas e profissionais, confiança pessoal, etc., dos que partem. A experiência passada de migrações temporárias para outras áreas rurais e para a cidade facilitou a aceitação da ideia de partir definitivamente. Desencadeado o movimento, os laços de parentesco tendem a dirigir os novos emigrantes para as áreas onde os primeiros se estabeleceram. São particularmente interessantes os resultados de diversos inquéritos concernentes aos motivos do êxodo, levados a cabo por vários autores e aqui recordados por HUGH CLOUT.

e) A percepção e o processo de tomada de decisões no despovoamento, perante a inadequação dos modelos gravitacionais assentes na distância entre o ponto de origem e o destino dos emigrantes e nas diferenças qualitativas dos dois lugares. $O$ emigrante consideraria o campo trepulsivo o a cidade ntractiva, mas na sua decisão de partir jogariam factores diversos: as próprias aspirações, o apego ou o distanciamento da sua comunidade, a condição social, as atitudes dos pais incitando-o ou dissuadindo-o, as obrigações familiares, etc. Retomando WOLPUT, o autor evocoll os três conceitos fundamentais no estudo do comportamento do emigrante: a utilidade dos possíveis lugares de destino em relação ìs suas aspiraçōes, qute têm por base a experiência pessoal e toda a informaçã recebida (à percepção de grupos de estímulos favoráveis ao êxodo deve-se juntar a reacção aos mesmos); a informação disponivel e a seleccionada pelo indivíduo (dependente da sua idade, edncação, viagens, contactos com amigos a familiares, aspirações, etc.); o encarar a vida como um ciclo, inclutindo ensino, casamento, procura de uma boa posição, promoção no emprego e reforma; tudo isto aondiciona as decisões de partida, até porque as migrações implicam transtornos e mudanças sociais para a família.

Ao terminar a análise da complexidade das migrações do campo para a cidade, CLOUT sublinhou a necessidade de novas investigações pluridisciplinares, sobretudo nos países em vias de desenvolvimuento $\theta$ urbanização, onde são insignificantes os fluxos inversos. Segundo o autor, aquelas deveriam interessar todos os especialistas das ciências sociais, desde a psicologia a geografia humana, passando pela sociologia e pela economia.

2. Aspectos sociais da vida rural. No cap. 3, CLoUT discute procura explicar as características próprias da vida rural, em oposiçño à das cidades. Começa por recordar opiniọes de diversos autores, louvando uma ou outra, do ponto de vista social. No passado consideravam-se rurais as áreas de fraca densidade, pequenos núcleos isolados, com modos de vida homogéneos e ligados à agricultura. Como variéveis de distinção das antigas condições de vida rural e urbana, aceitou: tipo de emprego, ambiente, tamanho da comunidade, densidade e homogeneidade da população, diferenciação, social, mobilidade e interacção social.

Alguns especialistas de ciências sociais reconheceram diferentes graus cle ruralidade e de urbanização e colocaram-nos numa escala ordenada desde 10 autenticamente rural ao autenticamente urbano. No livro apontam-se exemplos sugestivos da continuidade dos dois meios e da grande variedade de inter- 
-relações entre os seus habitantes, nos hinterlants das grandes cidades e thas áreas rurais procuradas por turistas e reformados, ou nos fins-de-semana. Também a estrutura social agrícola tende a mudar, à semelhança do que se observa nos EUA. „Em muitos países europeus, o problema é conseguir um ambiente em que possam viver e trabalhar com felicidade as pessoas de mentalidade urbana, mesmo em áreas rurais escassamente povoadas». Os termos rural e urbano serão hoje ambíguos: não temos a certeza de existirem diferencas significativas entre a população da cidade e do campo quanto aos modos de vida, esperanças, aspirações, atitudes, hábitos, etc.

Nos capítulos seguintes, CLOUT considerou as consequências do aumento da mobilidade pessoal e das diferentes mudanças sociais ocorridas em áreas de paisagem rural, e alguns dos problemas de ordenamento das que são sujeitas a novas pressões e mudanças nos recursos locais.

Os capítulos 4 e 5 foram dedicados à urbanização do campo. Esta pode resultar de vários processos e apresentar diversos matizes, tendo o antor considerado os seguintes:

a) $O$ aumento da riqueza, a eficácia dos transportes públioos o número crescente de automóveis particulares combinaram-se e permitiram que muitos habitantes da cidade fossem viver no campo, mas deslocando-se diariamente àquela para o trabalho, estudos, diversões, compras o serviços;

b) Membros das famílias camponesas trabalham na cidade mas continuam a viver no campo a a dedicar parte do seu tempo ao cultivo da terra;

c) Muitos citadinos procuram recrear-se no campo, ao ar livre, nos fins-de-semana e nas férias, em contacto mais ou menos intenso com os agricultores;

d) Outros adquirem casas no campo ou mandam construir aí residências secundárias.

Vejamos, resumidamente, alguns aspectos fundamentais das diferentes formas de urbanização do campo, consideradas pelo autor.

a) Migrações pendulares, urbanização difusa do campo e transformação das relaçóes cidade-campo, nas areas periurbanas. Isto verifica-se, sobretudo, nas áreas mais próximas das cidades e melhor servidas de transporte. Mas outros factores também interferem: regulamentações no uso do solo; políticas espaciais e desenvolvimento planeado de alguns núcleos; prestígio de certos lngares; mercado fundiário e atitude dos proprietírios perante as solicitações de compra da sua terra para construção de residências. Para a Grã-Bretanha, pode-se afirmar que uas mudancas nos hábitos de trabalho e no modo de vida foram tão rápidas durante os últimos anos, que as diferencas entre a cidade e o campo e entre as comunidades urbanas e rurais são cada vez mais difusas. O limite da cidade pode definir-se em termos formais pela passagem duma edificação contínua a formas de uso do solo menos intensivas, mas não terá correspondência em termos funcionais on sociais.

Os novos afluxos compensam o êxodo agrícola e asseguram a clientela necessária à rendibilidade dos estabelecimentos comerciais e dos serviços. Registam-se importantes alterações não só no uso da terra mas também sociais: afirmação numérica da classe média em muitos países ricos, a qual dispõe de meios que the permitem residir no campo (grande mobilidade espaoial, pelo grande número de antomóveis); frequente separação espacial entre a classe média e a trabalhadora; diferenciaçâo social mais complexa, com maior afastamento e segregação de grupos; etc.

"O lado externo de uma região metropolitana... é uma fronteira de mudanças sociais... mas as influências urbanas também podem ser difundidas no oampo por um processo inverso, quando os agricultores encontram empregos industriais na cidade, mas continuam a trabalhar as suas terras».

b) $O$ operário camponês; vantagens e desvantagens para a agricultura. o operário-camponês continua o seu trabalho no campo, às tardes, nos fins-cle-semana e nas férias mas adoptou uma mentalidade urbana; a agricultura persiste em posição secundária e até como ocupação recreativa. O fenómeno era conhecido na Europa nos finais do século XIX, mas teve o seu auge com 0 crescimento industrial posterior à $2{ }^{\text {a }}$ Grande Guerra, pelas novas facilidades dos transportes públicos e individuais; alargaram-se, paralelamente, as áreas de dispersão destas explorações agrícolas a tempo parcial (muito numerosas na Alemanha Federal, Polónia, no Maciço Central Francês, Alsácia, etc.), que foram bastante apreciadas, até por motivos de segurança, incluindo a alimentar.

A existência de operários-camponeses com rendimentos superiores aos exclusivamente agricolas ou industriais significa persistência de clientela capaz de assegurar viabilidade ao comércio e aos serviços, que também servem as populações exclusivamente agrícolas; além disso, parte dos ganhos são desviados para o equipamento mecânico da exploração (por vezes excessivo) e a introdução de inovações é, aliás, facilitada pelos contactos com o trabalho industrial. São, no entanto, empresas pequenas e parceladas, que dificultam o reordenamento fundiário e a constituiçãio de explorações viáveis, através do alargamento em superfície de algumas conduzidas por verdadeiros agrioultores.

A rendibilidade dos investimentos meoanicos e a produtividade agrícola são quase sempre baixas (utilização menos intensiva do solo; pousio social), em comparação com as da agricultura a tempo total.

"O desenvolvimento da classe de operírio-camponês soluciona os problemas do agricultor mas não os da agricultura», embora à custa duma vida de trabalho muito dura, cada vez menos aceite, sobretudo pelas mulheres e pelas novas gerações. Não há, todavia, nesta evolução, uma ruptura brusca entre os pontos de vista e os modos de vida rurais e urbanos.

A mecanização, automatizaçño e racionalização do trabalho industria reduzem o recrutamento de operários e dispensam os camponeses pouco produtivos e assícluos; as novas gerações procuram, por isso, empregos urbanos mais estáveis, quer continuem a residir no campo, quer se fixem definitivamente na cidade; aumenta, assim, o pousio social e o número de residências secundárias.

c) A urbanização do campo pela função recreativa. Depois da segunda Grande Guerra, em muitos países desenvolvidos, começon a ampliar-se o movimento dos citadinos em direcção ao campo, como lugar de repouso e recreio, em concorrência com as praias e até com os centros termais e a montanha.

Em termos gerais, é difícil avaliar os efeitos do turismo de massas nos próximos cem anos sobre os modelos actuais da sociedade rural da maior parte 
da Europa. Para as sociedades camponesas, principalmente, o impacto será muito profundo. O turismo incrementará a invasão urbana do campo; estimulará enormemente o processo de aquisição de ideias urbanas; e será um factor muito poderoso na transfarmação da socieldade rural do século $\mathrm{XX}$ e na criação de novas formas sociais e de estruturas, que nos meados do século xxI serão radicalmente distintas das actuais. Resumindo, acelerará consideravelmente a tendência para a urbanização do campo.

O livro de CLoUT, que estamos a seguir, prolonga-se por outros capitulos (6 a 13) dedicados à planificaçáo do usso da terra, às mudanças estruturais da agricultura, à silvicultura como forma de aproveitamento do espaço, à valorização da paisagem, à racionalização do povoamento do campo, às vantagens e desvantagens da dispersão de indústrias, ao transporte de passageiros nas áreas murais da Grã-Bretanha e ao ordenamento integrado do campo, sempre apoiaclo em exemp. ingleses.

\section{C) Turismo e meio rural}

O campo como lugar de repouso e de férias dos citadinos foi abordado por CLOUT, no livro que acabámos de referir, e constituin tema de muitas outras obras, das quais apresentamos a de H. de FARCY e Ph. de GUNzBOURG, Tourisme et Milieu Rural. Un débouché rentable pour l'agriculture, Flammarion, Paris, 1967,219 p.

Este livro baseia-se, essencialmente, na experiência francesa e compreende duas partes: na primeira $-O$ que se pode fazer? - aprecia-se a participação efectiva dos agricultores em termos de alojamento, venda de produtos, organizaçño de distracções, prestação de senviços, ete.; na segunda - Como ter êxito? Que tipo de estrutura adoptar? - analisam-se a complexidade e as dificuldades dessa participação, as possíveis formas de ajuda e os tipos de acção em comum que se devem desenvolver. Encontra-se nele uma constante preocupação prática, assinalando possibilidades e caminhos a percorrer pelos agricultores franceses interessados em responder a esta nova procura turística, à semelhança dos austríacos, escoceses, polacos, jingoslavos, etc.

Os autores referiram, em primeiro lugar, a amplitude do movimento de férias dos franceses, a sua elasticidade, as formas de alojamento e os destinos, entre os quais terá papel progressivamete crescénte o meio rural se, além de alojamento, calma, ar puro, abastecimentos..., souber proporcionar contactos sociais, conhecimentos novos e distracções.

Isto pressupõe receptividade das populações rurais, condições mínimas de equipamento e de confonto doméstico e investimentos vários, para o aue poderão contar com subsidios e empréstimos oficiais. As vantagens económicas do turismo rural não se limitam aos alugueres de casas e quartos mobilados: acrescentem-se as da venda directa dos produtos (frutas, legumes, bebidas e ovos), retendo parte das margens de distribuição, o que aliás não é fácil (heterogeneidade do aspecto da oferta; comportamento do veraneante, com gosto tempo de se passear pelos estabelecimentos do centro mais próximo; perdas de tempo, à espera de clientela; dificuldade de escoar os excedentes), salvo em casos de contrato com colectividades, como as colónias de férias, de organização colectiva da oferta ou de barracas de venda à beira das estradas de grande movimento suburbano nos fins-de-semana; e, ainda, a venda de artigos do artesanato, fabricados durante os períodos mortos do calendário agrícola, e a do próprio trabalho, através da prestação de serviços diversos, incluindo os de guarda de crianças, de restaurante, lavandaria, etc. As vantagens económicas devem-se juntar as de encontro, convívio, troca de ideias e informação entre camponeses e veraneantes urbanos.

Os afluxos poderão ser avolumados com o alargamento da capacidade de recepção, através da multiplicação de casas e quartos mobilados, de colónias de férias e albergues de juventude, de parques de campismo acessiveis e devidamente equipados em termos recreativos e desportivos, de pensões e hotéis e da multiplicação de residências secundárias.

Aos agricultores cabe igualmente a multiplicação das distraç̧̃es: equitação popular; criação e aluguer de cavalos; organização de passeios; criação de caça e exploração de terrenos devidamente enriquecidos de perdizes, etc.; criação de peixes e construção e exploração de lagos e rios (praia, piscina, vela, esqui náutico, etc.); insta lação de golfes nústicos; ensino do artesanato, etc.

A presença de visitantes durante uma parte do ano ajuda a manter uma major vida local, permite a renovação de aglomerados muitos marcados pelo exodo, justifica certos equipamentos e infra-estmuturas, e com eles novos empregos, mesmo se estes visitantes são filhos do lugar. A agricultura tende a passar a uma actividade secundária, já que as actividlades ligadas ao turismo são mais remuneradoras, prestigiantes (se requerem certa especialização profissional e pelo contacto com o visitante) e de lucros menos incertos. Ao mesmo tempo, a comunidade local desintegra-se, pela intensificaçño da concorrência e do individualismo. Surgem novos critérios de avaliação do solo e do meio rural, que de repulsivo pode tornar-se atractivo, e inevitavelmente alguns conflitos, já que nem todos os habitantes participarão nos benefícios materiais directos a alguns serão condicionados nas suas aspirações agrícolas pelos valores turísticos (precos das parcelas e difícil alargamento da área das exploraçõos).

O êxito depende de uma certa concentração dos serviços dirigidos aos visitantes. A gestão dos conjuntos é muitas vezes difícil e pede a intervenção das colectividacles. Os agricultores devem sempre participar, pelo menos tha prestação de serviços; ada multiplicidade destas actividades nasce a vitalidade da sua região».

$\mathrm{Na}$ segunda parte do livro, os autores apreciam várias experiências de desenvolvimento de turismo social, as correspondentes dificuldades e os êxitos, salientando a necessidade de organização como condição dos mesmos. Foram considerados: a experiência americana de venda de serviços aos turistas por parte dos agricultores, que contaram com grande apoio oficial; os desportos de Inverno; as aldeias de férias, as gitteis familiares, as estâncias-verdes de férias e os parques rëgionais; e, por último, a difusão de residências secundárias e a dispersão de unidades industriais una clorofila».

Em seguida, os autores referem os problemas complexos que los promotores terão de enfrentar: sazonalidade das actividades turisticas, logo emprego 
irregular e subemprego; clientela que se não fixa; fraca aceitação por parte de muitos agricultores o conflitos psicológicos graves, derivados do contacto de uma sociedade isolada e tradicional com forasteiros urbanos; acesso aos capitais e gestão racional dos mesmos, incluindo o prolongamento da estação e o pleno emprego das instalações; tensões quanto ao uso do solo; disciplina do mercado fundiário; expropriações e indemnizações; motivação das populações locais; desenvolvimento de formas de participação colectiva na propriedade, nas actividades e nos lucros; conservação da paisagem e desenvolvimento da agricultura, que fixe a população, a qual defenderá e vigiará duranto todo o ano as infra-estruturas turisticas.

"Necessária ao turismo, a modernização da agricultura é ainda mais urgente para os próprios agricultores! Nas regiôes de férias eles estão muitas vezes em contacto com a fracção mais dinâmica da população urbana. Se não progridem, quantos desequilíbrios e feridas psicológicas! Os técnicos agrícolas deverão ser capazes de ajudar os agricultores a aproveitar plenamente as virtualidades devidas à chegada de veranentes, através da dlifusão de informação, de organização de acções comuns e até da criação de cooperativas de serviços ou de secçóes de turismo nas cooperativas polivalentes.

o ensino dirigido a meio rural deveria visar a formação dos agricultores em matéria de recepçño de hóspedes, incluindo decoração da casa, preparação racional de refeições e conhecimentos de história local e de uma língua estrangeira.

A terminar, os antores analisam as relações entre o turismo tural e o desenvolvimento regional: criação de actividades e de emprego, mas desequulibrada, se contasse apenas com a clientela em férias. Ao desenvolvimento turístico deve associar-se o de ontras actividades, agricolas e industriais. $A$ importância do turismo neste desenvolvimento está também na abertura do espirito, factor essencial do progresso.

\section{D) A Agricultura Portuguesa no Limiar da Reforma Agrária}

É este o título dum livro recente de E. de CASTro CaLdas (Instituto Gulbenkian de Ciência, CEEA, Oeiras, 1978, 235 + anexo estatístico), que consideramos fundamental na biblioteca dos professores de Geografia do nosso país.

O livro compreende duas partes - A Sequência dos Factos e das Situações Agrárias; A Sedimentação dos Factos e das Situações Agrírias - precedidas de uma Introdıção e dando lugar a uma Reflexão Final: $A$ Agricultura perante outras actividades económicas e sociais.

O autor utilizou ua sequência dos factos e das situações agrátias como instrumento de apoio à teoria explicativa do que em dada fase se nos depara sedimentado». A fase fundamental no estudo corresponde à que chegou ao 25 de Abril de 1974, liminr da Reforma Agrária quando, "a diferentes niveis das actividades produtivas e ao longo dos circuitos de distribuição de bens e serviços, as estruturas agrárias portuguesas, na sua expressão nacional on em stas assimetrias regionais, constituem o obstáculo mais relevante que continua a impedir um esforço eficaz de modernização da agricultura».
Recordando o peso esmagador de estruturas patológicas, numa óptica de funcionamento sócio-económico, o autor assinala, na Introdução, que "o impulso de motivações diferentes e de orgânicas desigualmente sedimentadas por um processo cumulativo de factos e de situações históricas, implantou no solo português actividades que tanto explicam o propósito de consumo directo da produção agrária, que chega a traduzir um esforço de sobrevivência nas situações ecológioas mais severas, como servem de fundamento a especulações voltadas para o mercado interno on externo". Daí a diversidade de paisagens e de aproveitamento do território, mas também a estagnação da produção e as dificuldades de abastecimento do mercado, pelo próprio declínio das sobras da economia de subsistência e pela ausência de orientação política, com largos reflexos no desequilíbrio da balança comercial e na população agrícola, os quais também foram analisados: "a análise demográfica basta para descortinar frustrações graves nos desenvolvimentos pelo menos regionais».

A finalizar a Introdução, o antor recorda to esmagamento que ameaça a agricultura, pelo desvio dos centros de decisc̃o para a indústria, para o comércio, para o urbanismo, para a tecnocracia, e para outros redutos do poder económico, social e políticon.

A Primeira Parte - A Sequência dos Factos e das Situações Agririas pp. 23-98-começa com a apresentação sumária das condições geofísicas que se oferecem à agricultura portuguesa e das técnicas agrárias primitivas, e prolonga-se com a da instalação do primeiro sistema agrário organizado e de novos sistemas agrários, de que conclui «a agricultura portuguesa não perdeu a feição económica de uma actividade de subsistência, sem deixar de basear-se num sistema social que impunha aos camponeses a pesada carga de fortes tributos senhoriais e os vexames das subordinações ainda de sabor servil»,

Segue-se a apreciação do esforço frustrado de modernização da agricultura, no século XIX, através das leis de Mouzinho da Silveira, "pelo bloqueamento estabelecido pelos que desviaram em seu proveito, nas Oâmaras Legislativas e no tráfico de influências clos Partidos, uma reforma de objectivos nacionais». Ao longo deste sécnlo verificou-se o avolumar da questão agrária, sobretudo no Alentejo, com a política de preços do trigo, apoiada pelos latifundiários, uque assim mantiveram e fortaleceram as estruturas básicas do capitalismo agrárion.

Depois, "com a implantação da República a questão agrária não alcança adeptos nem determina correntes de opinião suficientemente fortes e esclarecidas (...). O país concreto, alheado das manobras obscuras dos políticos urbanos e indiferente ao debate académico das ideologias, mantinha no Norte e no Centro fortíssimo comando do seu sistema agrário de subsistência. Na planície ondulada do Sul a economia de mercado dominava na grande empresa patronal». Consideramos particularmente clara e viva a evocaç̃o da vida dos trabalhadores do Sul (pág. 61).

E. de CASTRO CALDAS debruça-se, em seguida, sobre As tentativals de uma experiência aparentemente tecnocrática, através da Campanha do Trigo, da Colonização Interna, do Povoamento Florestal e de obras de Hidrúulica Agricola. Mas wo efeito económico e social das obras ficava neutralizado pela 
resistência à transformação que o regadio impunha e assistia-se à escandalosa apropriação privada da mais-valia dos empneendimentos financiados por recursos nacionais (...). Construídas as barragens por eficácia indiscutivel da engenharia agrícola, a obra de fomento hidroagríoola ficon apenas com a barragem inaugurada. A águi disponível correu nos canais de rega e foi manuseada, em grande, pelos especuladores do arroz e depois, do tomate, aproveitando as oportuniclades das estruturas agrárias existentes».

No campo organizativo, foram apreciados os Grémios da Lavoura, as Casas do Povo, os diferentes Organismos de Coordenação Económica, de âmbito sectorial (Juntas, Institutos, Comissões Reguladoras, Federaçóes), e o paralelo uesmagamento do movimento associativo dos agrioultores, partioularmente a sua expressão cooperativa».

A finalizar a I Parte, o autor considerou $O$ primeiro ensaio da tecnocracia finalmente instalada, no quadro dos diferentes Planos de Fomento, que se seguiram desde os meados do século. "Os seis anos do II Plano de Fomento decorreram sem que fosse tentada a experiência nem sequer de um moderado intervencionismo mas estruturas agrárias (...), o Produto Bruto Agrícola permanece estacionário e os rurais entram em êxodo espectacular e desesperado...., Trata-se, aliás, em todos os casos, de planos intencionalmente indicativos, quase formais, ununca determinando qualquer espécie de adesão sentimental por parte dos beneficiários».

A "tecnocracia" que os concebia estava muito afastada do país concreto: faltava informação estatística, sócio-económica, etc. "Com a oriação do Secretariado nasceu o local onde os objectivos do Plano passaram a ser fabricados".

$\mathrm{Na}$ adesão à EFTA, «as cláusulas de salvaguarda defendiam os nossos atrasos agrários contra a agressividade de produtos de altíssima qualidade oferecidos a preço competitivo por alguns dos parceiros». As negociações com a CEE, desde 1962, "revelaram a necessidade de considerar para a nossa agrjcultura as adaptações estruturais indispensáveis para se encontrar uma unnficação europeia de políticas agrícolas», sem o que não haveria acordo, e muito menos adest̃o.

O III Plano, todavia, confiou una capacidade de adaptação estrutural da agricultura, desde que um certo número de medidas fossem criadas»: subsidios, crédito, política de preços. É também significativo que novo diagnóstico sobre a situação da agricultura portuguesa tenha sido feito em 1969, por uma Missão do Banco Internacional de Reconstrução e Desenvolvimento.

$\mathrm{Na}$ preparação do IV Plano de Fomento unão havia lugar para propostas reformistas e mesmo ontras determinavam reservas caso se afastassem do que era usual como medida de acção indirecta», de que são exemplos as de clesenvolvimento de pastagens e de produçĩo pecuária, matadouros industriais, introdução de beterraba sacarina, defesa ecológica desempenhada pelas florestas, etc.». "No periodo contemporâneo, e particularmente em Portugal, a aparente tecnicidade dos mecanismos da existência humana adulterou a compreensão da essência dos factos sociais».

"O Mundo Rural profundamente dividido no sell conteńdo estrutural e humano, com um Norte e um Centro camponeses e um Sul dominantemente assalariado, sentia o abalo de um renovado desprendimento de velhas contradições agráriass.

Ao terminarmos esta apresentação sumária da I Parte deste livro, não queremos deixar de sublinhar, de novo, o interesse e reflexão que deve merecer, de todo o ensinante de Geografia de Portngal, esta densa apreciação das situações agrárias do século XIX e sobretudo do século XX.

Na II Parte-A Sedimentação dos Factos e das Situações Agrärias - o autor começa por apreciar o aproveitamento agrário actual do território, confrontando-o com o de 1875, a abertura do território a uma agricultura alargada, após quebra do isolamento e dinamização do comércio, com o melhoramento dos transportes (vinha, trigo), e as perspectivas do aproveitamento agrário do território.

No segunido capitulo são analisadas as Estruturas Agrárias, atendendo à informação do Inquérito ùs Explorações Agrícolns de 1968, aos baldios e matas nacionais, às estruturas sociais ỉa população agrícofa, às indústrias agrícolas e sụns estruturas, ao comércio agrícola, às estruturas da oferta e à posição da oferta perante a procura.

O capítulo III centrou-se nos Aspectos Económicos e Sociais da Produção Agricola, com particular relevo para os dados do P.A.B., a produtividade da terra e do trabalho e as largas margens de alterações possiveis.

No capítulo IV foi estudado o Comércio Externo de Produtos Agrários: composição e evolução das exportações, preços, confronto com as importações de produtos da agricultura, seu significado no comércio externo global e as orientações a extrair para a produção.

O V capítulo tem como tema o Crédito Agrícola. O autor recorda as suas origens remotas e a sua evolução até à actualidade, aponta a pesada e complexa máquina do Crédito Agrícola e a posição do Estado, da Banca e dos agricultores.

O nssociativismo agrícola foi apreciado no capítulo VI: as associações existentes em 1974, as tendências de fundo para to associativismo agrírio e as diferentes expressões da entreajuda.

No último capitulo analisaram-se e interpretaram-se dados demográficos agrícolas: número de activos e evolução, condições na profissão, repartição espacia1, formação profissional, êxodo e emigração.

A Reflexão Final salienta a clependência crescente da agricultura de outros sectores de actividade, exercendo pressões esmagadoras a montante e a jusante. "Tenta-se definir uma perspectiva da agricultura na sociedado global em mudança, que oferecerá o enquadramento natural das medidas de Reforma Agrária que a Agricultura Portuguesa aconselha ou impõe».

\section{E) Portugal. Agricultura e Problemas Humands}

Acerca dos problemas da agricultura portuguesa apareceu, mais recentemente, o livro de GONÇALO SANTA-RITA, Portugal, Agricultura e Problemas Humanos, Colecção Problemas Quotidianos, Terra Livre, Lisboa, 1979, 193 p. 
No espírito da colecção, este livro visa alcançar um público numeroso e não especializado profissionalmente, mas interessado nos problemas actuais do nosso mundo rural. A sua leitura critica é do igual modo aconselhada a professores do Geografia do Ensino Secundário, como uobra de informação e síntese» e também como ponto de partida e motivação de novas leituras. É, aliás, com muito agrado, que se salienta o interesse e consideração do autor pela Geografja, bem evidente ao longo do trabalho. Discordamos, todavia, da sua selecção de documentos cartográficos ilustrativos.

O livro começa por uma apreciação do meio físico e dos seus condicionalismos à implantação do homem, tendo em conta a evolução do seu conhecimento nos últimos cem anos: geologia, relevo, solo, regime das águas, clima e vegetação, na sua diversidade espacial. "Designações tradicionais, para as manchas de barros, areias, terras galegas, para zonas restritas como o Campo Branco, definem aptidões culturais, imposições nem sempre vencidas pelo homem, mas antes ladeadas através de rotinas milenares, quanto aos problemas de rega, drenagem, mobilização do solo, rotação de culturas, natureza de cobertura vegetal». No entanto, o antor pensa que «razões mais de ordem humana e institucional que condicionalismos geográficos, têm limitado a utilização integral e racional das potencialidades dos diversos compartimentos do território... Mais do que problemas geográficos, o aproveitamento do solo tem sido condicionado por problemas humanos e pela falta de decisões colectivas.»

O estudo prossegue com a análise da Condição Humana. Recorda a insuficiência e desactualização de dados estatísticos, a escassez de estudos sociológicos, o peso da agricultura doméstica, o baixo nível de produção, de alimentação e de vida da população rural, as condições estruturais da agricultura, os sistemas obsoletos de fruição e posse da terra, o atraso técnico, a emigração e o êxodo para as principais regióes urbanas e industriais, as unicns verdadeiramente atractivas, com a desertificação de vastas áreas do interior. A análise da situação na profissão da popnlação agrícola, permite-lhe evidenciar a falta quase geral de verdadeiros empresários agricolas e a esmagadora dominância de assalariados nos distritos do Sul, apesar do êxodo, que tornava inevitável a ruptura das instituiçôes. No Norte, uutilizando as potencialidardes da associação, emparcelamento, agricultura de grupo... não era difícil partir para uma europeização da lavoura...; nas regióes latifundiárias teria sido fácil reduzir - dualismo da sociedade portugnesa se não tivesse havido a persistência influência de quadros ideológicos que absolutizam direitos adquiridos on idealizam situações tradicionais, procurando as classes superiores, pelo recurso à moderna tecnologia, conservar tuma sociedade "tradicionalista, introduzindo-lhe uma agricultura modernizadan.

O livro continua com a apreciação dos Camponeses na História, sublinhando-se a sua marginalização no longo dos tempos, aliás reforçada por falta de verdadeiros centros urbanos regionais, polarizadores e estimulantes do interior, como recorda no parágrafo Rural e Urbano. Em seguida, o autor debruça-se sobre $A$ Terra $e$ o seu Amanho, salientando "que o reforço do poderio político de uma plutocracia aumentou a concentração do latifúndio e da coutada. Na zona do minifúndio, o factor de prestígio representado pela posse da terra, nomeadamente por parte do emigrante, aliađo à falta de actualização tecnológica da lavoura, constitui sério obstáculo a qualquer novo arranjo fundiário». São depois apreciados uo arranjo fundiário, as formas de exploração, a dimensão, organização, gestão, eficiência económica de cada lavoura, entendida como unidade estrutural da agricultura de uma região»; nestes aspectos procura assentar a caracterização dos diferentes génetos de vida, no sentido em que foram definidos por MAX SORRE («conjunto de práticas consolidadas pela tradição e através das quais o grupo humano subsiste num certo meio físico»), e o planeamento de novas explorações ou de novos sistemas de exploração em função do género de vida desejável.

Salientou-se, para o Sul, o Opróbio dos pousios, em contraste com a policultura da fachada atlântica, e muitos outros opróbios de distribuição espacial das culturas, de variedades, de produção por hectare, de nível técnico, de interdições a cultivos novos, como beterraba, tabaco, etc. O autor prossegue com Onde produz o Território, prendendo-se com as zonas fitoclimáticas, os diferentes sistemas ngricolas, o significado económico das diferentes produções a nível nacional e regional, as produtividades da terra e do trabalho, a densidade pecuária e o grau de tractorização. Seguem-se referências ao Meio e Técnica, com destaque para as inovações no cultivo (difusão de novos cultivos e de novas técnicas) e para a expansão do regadio (em termos culturais e técnicos correctos), à Vivência Colectiva (do associativismo tradicional à cooperação moderna) e à reforma agrária.

A última parte do livro foi intitulada $A$ Via Futurológica, e tem particular incidência na qualificação do lavrador: esta "só pode ser conseguida se a estrutura económica da exploração, a sua técnica e o seu arranjo físico forem orientados no sentido de alterar os padrões tradicionais de produção e de criar explorações orientadlas para o mercado. Isto pressugõe assistência técnica e serviços de extensão rural verdađeiramente adequados às necessidades do agricultor português».

"A análise económica, à investigação agronómica, à divulgação, tem de sobrepor-se a pesquisa sociológica e a educação permanente que transforme o campónio em lavrador. Produzindo em condições de abastecer o mercado - agricultor tem de elevar as produções, rednzir os custos, especializar-se, associar-se, promover a realização de economias de escala». Dai também as referêpcias ao êxodo de activos agrícolas ou de filhos de activos agrícolas $e$ ao desenvolvimento de actividades para-agricolas, ligadas economicamente à lavoura, a montante e a jusante (integração cooperativa global?); o carácter sazonal das últimas levanta, porém, problemas delicados de emprego e de utilização das infra-estruturas (recorde-se que, em 1975, dos 13000 operários das fábricas de concentrado de tomate, só $2 \%$ eram permanentes).

O lỉvro termina ciin Camiinhos da Prospecção, onde se analisam tendêncjas de evolução, projecçôes de consumo e necessárias orientações da produção, com vista a um maior equilibrio nas capitações de alimentos e na balança comercial.

CARMINDA CAYACO 